\title{
Attitudes and Perceptions of Healthcare Providers towards Clinical Pharmacy Services at a Tertiary Care Hospital in Riyadh, Saudi Arabia
}

\author{
Mohamed N Al-Arifi ${ }^{1 *}$, B Alghamdi ${ }^{1}$, M Al-Saadi $^{2}$, AE Idris ${ }^{1}$, Syed Wajid ${ }^{1}$, Ragab \\ Said $^{3}$ and Salmeen D Babelghaith ${ }^{1}$
}

${ }^{1}$ Clinical Pharmacy Department, Drug and Poison Information Center, College of Pharmacy, ${ }^{2}$ College of Medicine King Saud Univeristy, ${ }^{3}$ Al Maarefa College of Pharmacy, Riyadh Saudi, Arabia

*For correspondence: Email: malarifi@ksu.edu.sa; Tel: +96614677352; Fax: +96614674229

\begin{abstract}
Purpose: To evaluate the attitudes and perceptions of health care providers towards clinical pharmacy services at King Khalid University Hospital Riyadh Saudi Arabia

Method: A cross-sectional survey of healthcare providers was conducted in King Khalid University Hospital, Riyadh, Saudi Arabia from September to November 2013. A self-administered questionnaire was delivered to health care professionals (HCPs) who included physicians, pharmacists and nurses. Results: The response rate was $78 \%(457 / 600)$. The majority of the respondents $(92.4 \%)$ knew that the clinical pharmacist is an integral part of the medical team while $86.5 \%$ of the participants expressed confidence in the ability of clinical pharmacists to improve the quality of patient care through their practice. Despite the relative lack of awareness of the increasing interest in clinical pharmacy practice (59.6\% were not aware of such a trend), pharmacists were less appreciative $(p<0.05)$ of the positive role of clinical pharmacists in direct patient care compared to both physicians and nurses (67.4, 74.3 and $72.3 \%$, respectively).

Conclusion: The findings of this study reveal that health care professionals HCPs have positive attitude towards the role of the clinical pharmacist in the health care setting studied. However, there is a need for Saudi hospitals to adopt full clinical pharmacy service including drug monitoring, drug information and pharmacotherapy for enhanced health care.
\end{abstract}

Keywords: Saudi Arabia, Clinical pharmacy services, Healthcare professionals, Attitude, Patient care

Tropical Journal of Pharmaceutical Research is indexed by Science Citation Index (SciSearch), Scopus, International Pharmaceutical Abstract, Chemical Abstracts, Embase, Index Copernicus, EBSCO, African Index Medicus, JournalSeek, Journal Citation Reports/Science Edition, Directory of Open Access Journals (DOAJ), African Journal Online, Bioline International, Open-J-Gate and Pharmacy Abstracts

\section{INTRODUCTION}

Clinical pharmacy is a health science discipline in which pharmacists provide patient care that optimizes medication therapy and promotes health, wellness, and disease prevention [1]. This field of pharmacy practice focuses on patientoriented rather than drug product-oriented service [2]. The typical role of clinical pharmacists involves ensuring appropriate prescription and administration of the correct medicine to the right patient in the appropriate dose through the proper route of administration. In addition clinical pharmacist are to monitor patient adherence to therapy, provide drug information, monitor patient responses and laboratory values, and provide patient and provider education. Other responsibilities carried out by clinical pharmacists may include but are not limited to: prevention of medication errors, 
improvement of therapeutic outcomes, performing patient counseling, and maximization of cost-effectiveness of drug therapy. However, in order to perform these tasks efficiently an advanced level of collaboration must exist between clinical pharmacists and other healthcare providers which will not only improve the patients' pharmacotherapeutic outcomes but also will enhance the efficiency of the healthcare system as a whole [3].

Clinical pharmacists are a principal source of evidence-based drug information for improved safe and appropriate use of medications [1]. Several studies have been conducted in some Arab countries to assess physicians' acceptance of the clinical pharmacists' role in the healthcare system. In Jordan, $63 \%$ of physicians expect the pharmacist to educate their patients with regard to the safe and appropriate use of drugs [4].

In addition, approximately half of the physicians agreed that pharmacists were always a reliable source of drug information [4]. In a similar study conducted in Sudan, physicians were found to be 'uncomfortable' with pharmacists suggesting or recommending medications to their patients [5], especially as collaboration between the physician and pharmacist has been described as a 'difficult one' [5]. Other studies have reported the existence of communication gap between pharmacists and physicians $[6,7]$

The current health system in the Middle East still falls short of expectations, as some studies have found that although physicians are comfortable with the role of pharmacist in patient counseling, they are, however, uncomfortable with pharmacists participating in direct patient care and clinical rounds [8,9]. One study suggested that low acceptance by physicians of the role of the pharmacist in direct patient care is due to poor collaboration between physicians and pharmacists [10].

The aim of this study was to evaluate the attitudes and perceptions of health care providers towards clinicla pharmacy servicess at King Khalid University Hospital (KKUH), Riyadh, Saudi Arabia, and to proffer solutions to overcome the challenges.

\section{EXPERIMENTAL}

A cross-sectional survey of healthcare providers was conducted in King Khalid University Hospital KKUH Saudi Arabia between September and
November 2013. Data collection was carried out using a structured self-administered questionnaire. The study was approved by institutional review board (IRB) from King Saud University College of Medicine (approval ref no. 12/3260/IRB). A total of 600 questionnaires were distributed by convenience sampling; sample size was estimated from a previous published study [8].

The pharmacy department at King Khalid University Hospital (KKUH) was the first pharmacy department to implement clinical pharmacy program outside the United States of America (USA). This service was established in 1983 with a clinical pharmacist, with 15 clinical pharmacists employed after the initial trial. Subsequently, the service was expanded to cover all hospitals clinical disciplines [11]. Included in the study were all health care providers (physicians, nurses, pharmacists as well as other health care professionals and technicians. Clinical pharmacists were excluded from the study.

The questionnaire was written in English language and developed from review of the literature and previous studies relating to the clinical pharmacy services [12]. The survey questions were pre-tested by health care providers with extensive experience in clinical pharmacy services. A pilot study of 20 participants was carried out to check for readability, understanding, question design and the length of the questionnaire. Based on the result of this pilot study the questionnaire was used with some modifications. The questionnaires were self-administered.

The questionnaire composed of three sections. The first section consisted of six items that mainly focused on the demographic information of the respondents, their experience and current position in the hospital. Section two explored the importance of clinical pharmacist in health care settings, and consisted of ten statements. Respondents were asked to rate their response to these statements using 4 options, "agree", "neutral", "disagree", or "I don't know". The last section consisted of four questions on clinical pharmacist role in health care sector using a four-point Likert-type scale "agree", "neutral", "disagree", or "I don't know".

\section{Data analysis}

The data were entered into SPSS version 21 for Windows for analysis. Both descriptive and analytic statistics were applied. For descriptive analysis, results were expressed as numbers 
and percentages $(95 \% \mathrm{Cl})$. Chi-squared and Fisher's exact tests were used to find statistically significant difference among the participants with $p<0.05$ considered statistically significant.

\section{RESULTS}

A total of 422 questionnaires were appropriately filled, giving a response rate of $78 \%$. The demographic characteristics of the respondents were summarized in Table 1. About $76 \%(n=$ 321 ) of respondents were under 46 years old. Almost eight-tenth of the respondents were female $(78.7 \%)$ and non-Saudis $(79.6 \%)$. The majority of respondents are junior healthcare providers $(82.7 \%)$ while only $13.7 \%$ senior healthcare providers. With regard to participants' professions, $68.7 \%$ were nurses, $17.5 \%$ were physicians, $10.9 \%$ were pharmacists and $2.8 \%$ other healthcare providers. The majority of the respondents $73.9 \%$ obtained their qualifications from either (North America or Europe) or other countries respectively while $21.3 \%$ of participants obtained their qualification degree from Saudi Arabia.

The results show that healthcare providers' had positive attitude toward the roles of clinical pharmacists regardless of their profession. The majority of them reported that the clinical pharmacist is an important and integral part of the medical team and that they believe in clinical pharmacists' capacity to improve the quality of patient care in hospital setting (92.4 and $86.5 \%$, respectively). More than $85 \%$ agreed that the presence of clinical pharmacists in the medical team is essential for hospital accreditation and that they contribute to reduction of medication errors and improvement of therapeutic outcomes. However, majority of respondents (70 \%) reported that the clinical pharmacists need training in different medical areas to perform patient counseling less than $50 \%$ of respondents stated that there is an increasing interest in clinical pharmacy as a profession in Saudi Arabia.

There were some statistical differences among different professions in regard to their response to the statements, pharmacists were significantly $(p<0.05)$ less appreciative of the role of clinical pharmacist in direct patient care with $67.4 \%$ agreeing versus 74.3 and $72.3 \%$ for both physicians and nurses respectively.

Table 1: Demographic profile of respondent healthcare providers

\begin{tabular}{|c|c|}
\hline Variable & Frequency \\
\hline \multicolumn{2}{|l|}{ Gender } \\
\hline Male & $90(21.3 \%)$ \\
\hline Female & $332(78.7 \%)$ \\
\hline \multicolumn{2}{|l|}{ Age } \\
\hline$<25$ years & $2(0.5 \%)$ \\
\hline $25-35$ years & $182(43.1 \%)$ \\
\hline $36-45$ years & $137(32.5 \%)$ \\
\hline $46-55$ years & $79(18.7 \%)$ \\
\hline 56 and above & $22(5.2 \%)$ \\
\hline \multicolumn{2}{|l|}{ Nationality } \\
\hline Saudi & $86(20.4 \%)$ \\
\hline Non-Saudi & $336(79.6 \%)$ \\
\hline \multicolumn{2}{|l|}{$\begin{array}{l}\text { Professional cadre } \\
\text { Physician }\end{array}$} \\
\hline Pharmacist & $74(17.5 \%)$ \\
\hline Nurse & $46(10.9 \%)$ \\
\hline $\begin{array}{l}\text { Other healthcare providers (Pharmacy \& Radiology Technicians, } \\
\text { Healthcare Assistant) }\end{array}$ & $\begin{array}{l}290(68.7 \%) \\
12(2.8 \%)\end{array}$ \\
\hline \multicolumn{2}{|l|}{ Professional classification } \\
\hline $\begin{array}{l}\text { Senior healthcare providers (consultant, senior registrar, registrar, } \\
\text { senior pharmacist, supervisor pharmacist, head nurse) }\end{array}$ & $58(13.7 \%)$ \\
\hline Junior healthcare providers (residents, intern, junior pharmacist, nurse) & $349(82.7 \%)$ \\
\hline $\begin{array}{l}\text { Other healthcare providers (Pharmacy tTechnician, Radiology } \\
\text { Technician, Healthcare Assistant) }\end{array}$ & $15(3.6 \%)$ \\
\hline \multicolumn{2}{|l|}{ Country of qualification } \\
\hline Saudi Arabia & $90(21.3 \%)$ \\
\hline North America or Europe & $9(2.1 \%)$ \\
\hline Other countries & $312(73.9 \%)$ \\
\hline Saudi Arabia and North America and/or Europe & $11(2.6 \%)$ \\
\hline
\end{tabular}


Pharmacists were also significantly $(p<0.05)$ less confident in the role of clinical pharmacist in improving the quality of patient care during medical rounds with $83 \%$ of them agreeing to the statement versus $92 \%$ of physicians. In regard to the ability of clinical pharmacist to minimize medication errors and improve therapeutic outcomes, $84.8 \%$ of pharmacists agreed to the statement compare to 92 and $88 \%$ for physicians and nurses, respectively. As for the role of pharmacists in maximization of costeffectiveness, respondents' opinions regarding the 10 statements are summarized in Table 2.

There was significantly $(I<0.05)$ less awareness about such roles, with $69 \%$ agreeing to statement on cost-effectiveness versus $81.1 \%$ and $80.4 \%$ of physicians and pharmacist, respectively. Table 3 illustrates the respondents' views on some of the study statements according to their profession.

Table 3 details respondents' views on some of the study statements according to their profession.

Considering professional classification, around $88 \%$ of senior healthcare providers had significantly $(p<0.05)$ more acceptance regarding the role of clinical pharmacist in direct patient care compare to $69.5 \%$ of junior staff and

Table 2: Opinions of healthcare providers on clinical pharmacy services

\begin{tabular}{|c|c|c|c|c|c|}
\hline Statement & $\begin{array}{l}\text { Agree } \\
\mathrm{N}(\%)\end{array}$ & $\begin{array}{l}\text { Neutral } \\
\mathrm{N}(\%)\end{array}$ & $\begin{array}{l}\text { Disagree } \\
\mathbf{N}(\%)\end{array}$ & $\begin{array}{l}\text { Idon't } \\
\text { know } \\
\text { N (\%) }\end{array}$ & $\begin{array}{l}\text { Missing } \\
\mathrm{N}(\%)\end{array}$ \\
\hline $\begin{array}{l}\text { Previously heard about clinical } \\
\text { pharmacy programs }\end{array}$ & $255(61.3 \%)$ & $65(15.6 \%)$ & $23(5.5 \%)$ & $73(17.5 \%)$ & $6(1.4 \%)$ \\
\hline $\begin{array}{l}\text { The clinical pharmacist is an important } \\
\text { and intearal part of the medical team }\end{array}$ & $389(92.4 \%)$ & $24(5.7 \%)$ & $1(0.2 \%)$ & $7(1.7 \%)$ & $1(0.2 \%)$ \\
\hline $\begin{array}{l}\text { The clinical pharmacist helps to } \\
\text { improve the quality of medical care in a } \\
\text { hospital setting }\end{array}$ & $360(86.5 \%)$ & $44(10.6 \%)$ & $6(1.4 \%)$ & $6(1.4 \%)$ & $6(1.4 \%)$ \\
\hline $\begin{array}{l}\text { The clinical pharmacist is trained to } \\
\text { perform patient counseling }\end{array}$ & $290(70 \%)$ & $69(16.7 \%)$ & $27(6.5 \%)$ & $28(6.8 \%)$ & $8(1.9 \%)$ \\
\hline $\begin{array}{l}\text { The clinical pharmacist as part of } \\
\text { medical teams is essential for hospital } \\
\text { accreditation }\end{array}$ & $372(88.4 \%)$ & $35(8.3 \%)$ & $3(0.7 \%)$ & $11(2.6 \%)$ & $1(0.2 \%)$ \\
\hline $\begin{array}{l}\text { The clinical pharmacist as part of } \\
\text { medical team minimizes medication } \\
\text { errors and improve patient therapeutic } \\
\text { outcomes }\end{array}$ & $370(88.1 \%)$ & $35(8.3 \%)$ & $10(2.4 \%)$ & $5(1.2 \%)$ & $2(0.5 \%)$ \\
\hline $\begin{array}{l}\text { There is increasing interest in clinical } \\
\text { pharmacy as a profession in Saudi } \\
\text { Arabia }\end{array}$ & $168(40.4 \%)$ & $108(26.0 \%)$ & $13(3.1 \%)$ & $127(30.5 \%)$ & $6(1.4 \%)$ \\
\hline $\begin{array}{l}\text { Doctors and other healthcare staff } \\
\text { accept the involvement of clinical } \\
\text { pharmacists in patient management } \\
\text { and provide extra service within the } \\
\text { framework of clinical pharmacy }\end{array}$ & $302(71.9 \%)$ & $81(19.3 \%)$ & $19(4.5 \%)$ & $18(4.3 \%)$ & $2(0.5 \%)$ \\
\hline $\begin{array}{l}\text { The presence of clinical pharmacist in } \\
\text { a clinical ward team improves the } \\
\text { quality of patient care in a hospital } \\
\text { setting }\end{array}$ & $346(82.2 \%)$ & $56(13.3 \%)$ & $7(1.7 \%)$ & $12(2.9 \%)$ & $1(0.2 \%)$ \\
\hline $\begin{array}{l}\text { I think that the clinical pharmacist is } \\
\text { able to maximize cost-effectiveness } \\
\text { and improve patient outcomes }\end{array}$ & $301(71.8 \%)$ & $90(21.5 \%)$ & $8(1.9 \%)$ & $20(4.8 \%)$ & $3(0.7 \%)$ \\
\hline
\end{tabular}


Table 2: Respondents views according to profession

\begin{tabular}{|c|c|c|c|c|c|c|}
\hline \multirow[t]{2}{*}{ Statement } & \multirow[t]{2}{*}{ Response } & \multicolumn{4}{|c|}{ Profession } & \multirow{2}{*}{$\begin{array}{c}\begin{array}{c}P \text { - } \\
\text { value }\end{array} \\
\mathbf{N}(\%)\end{array}$} \\
\hline & & $\begin{array}{c}\text { Physician } \\
N(\%)\end{array}$ & $\begin{array}{c}\text { Pharmacist } \\
N(\%)\end{array}$ & $\begin{array}{l}\text { Nurse } \\
N(\%)\end{array}$ & $\begin{array}{l}\text { Other } \\
N(\%)\end{array}$ & \\
\hline \multirow{4}{*}{$\begin{array}{l}\text { The clinical pharmacist helps } \\
\text { improving the quality of medical } \\
\text { care in a hospital setting }\end{array}$} & Agree & $67(90.5 \%)$ & $41(89.1 \%)$ & $242(85.2 \%)$ & $10(83.3 \%)$ & 0.034 \\
\hline & neutral & $7(9.5 \%)$ & $2(4.3 \%)$ & $35(12.3 \%)$ & $0(0.0 \%)$ & \\
\hline & disagree & $0(0.0 \%)$ & $2(4.3 \%)$ & $4(1.4 \%)$ & $0(0.0 \%)$ & \\
\hline & I don't know & $0(0.0 \%)$ & $1(2.2 \%)$ & $3(1.1 \%)$ & $2(16.7 \%)$ & \\
\hline \multirow{4}{*}{$\begin{array}{l}\text { Doctors and other healthcare } \\
\text { staff accept the involvement of } \\
\text { clinical pharmacists in patient } \\
\text { management and providing } \\
\text { extra service within the } \\
\text { framework of clinical pharmacy }\end{array}$} & Agree & $55(74.3 \%)$ & $31(67.4 \%)$ & 209 (72.3\%) & $7(63.6 \%)$ & 0.017 \\
\hline & neutral & $13(17.6 \%)$ & $7(15.2 \%)$ & $62(21.1 \%)$ & $0(0.0 \%)$ & \\
\hline & disagree & $4(5.4 \%)$ & $5(10.9 \%)$ & $9(3.1 \%)$ & $1(9.1 \%)$ & \\
\hline & I don't know & $2(2.7 \%)$ & $3(6.5 \%)$ & $10(3.5 \%)$ & $3(27.3 \%)$ & \\
\hline \multirow{4}{*}{$\begin{array}{l}\text { Clinical pharmacist as part of } \\
\text { medical teams minimizes } \\
\text { medication errors and improve } \\
\text { patient therapeutic outcomes }\end{array}$} & Agree & $68(91.9 \%)$ & $39(84.8 \%)$ & 254 (87.9\%) & $9(81.8 \%)$ & 0.027 \\
\hline & neutral & $6(8.1 \%)$ & $2(4.3 \%)$ & 27 (9.3\%) & $0(0.0 \%)$ & \\
\hline & disagree & $0(0.0 \%)$ & $4(8.7 \%)$ & $5(1.7 \%)$ & $1(9.1 \%)$ & \\
\hline & I don't know & $0(0.0 \%)$ & $1(2.2 \%)$ & $3(1.0 \%)$ & $1(9.1 \%)$ & \\
\hline \multirow{4}{*}{$\begin{array}{l}\text { I think that clinical pharmacist } \\
\text { able to maximize cost- } \\
\text { effectiveness and improve } \\
\text { patient outcomes }\end{array}$} & Agree & $60(81.1 \%)$ & 37 (80.4\%) & $198(69.0 \%)$ & $6(50.0 \%)$ & 0.025 \\
\hline & neutral & $12(16.2 \%)$ & $7(15.2 \%)$ & $68(23.7 \%)$ & $3(25.0 \%)$ & \\
\hline & disagree & $1(1.4 \%)$ & $2(4.3 \%)$ & $5(1.7 \%)$ & $0(0.0 \%)$ & \\
\hline & I don't know & $1(1.4 \%)$ & $0(0.0 \%)$ & $16(5.6 \%)$ & $3(25.0 \%)$ & \\
\hline
\end{tabular}

$88 \%$ of them also showed significantly $(p<0.05)$ more appreciation than junior healthcare providers $(82 \%)$ to the role of clinical pharmacist as a member of clinical ward team.

All of the participants who obtained their qualifications from either North America or Europe and Saudi Arabia accepted the involvement of clinical pharmacist in direct patient management, compared to $60 \%$ of participants who obtained their qualifications from only Saudi Arabia.

\section{DISCUSSION}

Pharmacists' scope of practice includes broad areas of professional responsibilities, ranging from the provision of traditional services of producing and distributing drug preparations to the non-traditional provision of pharmaceutical care [1]. Clinical pharmacy services involve optimizing patient outcomes by addressing a patient's medication-related needs in collaboration with the patient and other healthcare professionals.

Some of the studies done in this regard in Middle East suggested that physicians were uncomfortable with the role of clinical pharmacist in direct patient care $[8,9]$. However, in the current study physicians and other healthcare providers not only welcomed the role of clinical pharmacist in direct patient care but also they accepted the involvement of clinical pharmacists in patient management and, to some extent, the participation of clinical pharmacist as a member of clinical ward team. Healthcare providers at $\mathrm{KKUH}$ showed a good perception of the role of clinical pharmacist in improving patient outcomes.

Surprisingly, the pharmacists were less confident about the ability of clinical pharmacists to minimize medication errors and improve the therapeutic outcomes compare to physicians and nurses and also less appreciative to clinical pharmacist role in direct patient care. This somewhat pessimistic point of view of some pharmacists may be due to the presumption by many pharmacists that physicians are overwhelmingly disapproving the involvement of pharmacists in these aspects of patient care and this in turn may be attributed to lack of direct communication and inter-professional relationship between some pharmacists and physicians.

The results of the current study resemble those of similar study done in this regard at united arab emirates UAE [12]. The results reinforced the fact that clinical pharmacist should communicate positively with physicians and show them their capabilities in direct patient care. Some studies [11] suggested that clinical pharmacists should be encouraged to participate in direct patient care instead of administrative positions so that their impact on the quality of healthcare would be felt and fully appreciated. Focusing on physicianpharmacist relationship, a study conducted in University of lowa, found three factors to be significantly associated with collaborative care; 
trustworthiness, role specification and professional interaction [13 ].

\section{Limitations of the study}

The results of this study should be considered within the context of its limitations. First, sampling was done using convenience sampling and not based on stratification of participants according to their profession. Second, this study was conducted at King Khalid University Hospital and the results of the current study should not be extended to other hospitals where the level of clinical pharmacy implementation varies significantly. Third, the participants in this study included pharmacists who may be biased. Finally the questionnaire used was in English language. Since Arabic is the main language used in Saudi Arabia, the use of the English language might have constituted a barrier to the study's effectiveness.

\section{CONCLUSION}

The study shows that generally healthcare providers are willing to cooperate with clinical pharmacists in improving patient quality of care and that clinical pharmacists should increase their collaboration with physicians in order to improve their involvement in direct patient care. Inter-professional relationship between physicians and nurses on the one hand, and pharmacists on the other, should be emphasized in medical, nursing and pharmaceutical curricula. Furthermore, the role of the clinical pharmacist in the hospital healthcare team should be clearly defined and explained.

\section{REFERENCES}

1. American College of Clinical Pharmacy. The Definition of Clinical Pharmacy. Pharmacotherapy 2008; 28(6): 816-817.

2. Barker KN, Valentino JG. On a political and legal foundation for clinical pharmacy practice. J Am Pharm Assoc 1972; 12: 202-206
3. Hammond RW, Schwartz AH, Campbell MJ, Remington $T L$, Chuck S, Blair MM, Vassey AM, Rospond RM, Herner SJ, Webb CE. Collaborative drug therapy management by pharmacists. Pharmacotherapy 2003; 23(9):1210-1225.

4. Plagakis J. Don't call me, call the doc. Drug Trop 1997; 141: 167.

5. Ables AZ, Baughman OL, III. The clinical pharmacist as a preceptor in a family practice residency training program. Fam Med 2002; 34: 658-662.

6. Sulick JA, Pathak DS. The perceived influence of clinical pharmacy services on physician prescribing behavior: a matched-pair comparison of pharmacists and physicians. Pharmacotherapy 1996; 16: 1133-1141

7. Nesbit F, Chaplain DC, Edwards JA (Jr), Fleming GR, Harker MN, Work DR, Neelon FA. Counselling of patients by pharmacists. Blessing or curse? N C Med J 1995; 56: 115-118.

8. Tahaineh, LM, Wazaify M, Albsoul-Younes A, Khader Y, Zaidan M. Perceptions, experiences, and expectations of physicians in hospital settings in Jordan regarding the role of the pharmacist. Res Social Adm Pharm 2009; 5(1): 63-70.

9. Matowe L, Abahussain EA, Al-Saffar N, Bihzad SM, AlForaih A, Al-Kandery AA. Physicians' Perceptions and Expectations of Pharmacists' Professional Duties in Government Hospitals in Kuwait. Med Princ Pract 2006; 15: 185-189.

10. Bryant LJ, Coster G, Gamble GD, McCormick RN. General practitioners' and pharmacists' perceptions of the role of community pharmacists in delivering clinical services. Res Social Adm Pharm 2009; 5(4): 347-362.

11. Saddique AA. Development of Clinical Pharmacy services at King Khalid University Hospital and its impact on the quality of healthcare provided. Saudi Pharm J 2012; 20(3): 273-277

12. Abu-Gharbieh E, Fahmy S, Abdul Rasool B, Abdulkarem A, Basheti I .Attitudes and Perceptions of Healthcare Providers and Medical Students Towards Clinical Pharmacy Services in United Arab Emirates. Trop J Pharm Res 2010; 9(5): 421-430.

13. Doucette WR, Nevins J, McDonough RP. Factors affecting collaborative care between pharmacists and physicians. Res Social Adm Pharm 2005; 1(4): 565578. 